\title{
Congenital cytomegalovirus infection in high-risk Canadian infants: Report of a pilot screening study
}

\author{
Wendy Vaudry MDCM FRCPC ${ }^{1}$, Rhonda J Rosychuk PhD PStat ${ }^{1}$, Bonita E Lee MD MSc FRCPC ${ }^{1,2}$, \\ Po Yin Cheung MD PhD FRCPC ${ }^{1}$, XL Pang PhD², Jutta K Preiksaitis MD FRCPC ${ }^{2}$
}

W Vaudry, RJ Rosychuk, BE Lee, PY Cheung, XL Pang, JK Preiksaitis. Congenital cytomegalovirus infection in highrisk Canadian infants: Report of a pilot screening study. Can J Infect Dis Med Microbiol 2010;21(1):e12-e19.

OBJECTIVES: Congenital cytomegalovirus (cCMV) is the most common congenital infection; however, the epidemiology in Canada has not been recently examined. The present prospective study pilots tools for a population-based study of cCMV infection in Canada by determining the maternal seroprevalence and risk factors, the clinical characteristics and the incidence of cCMV using a variety of diagnostic tests in a cohort of high-risk infants in northern Alberta.

METHODS: All infants born at the Royal Alexandra Hospital in Edmonton, Alberta, from June 1, 2003, to May 31, 2004, were screened for the study. Eligible infants were those with very low birth weights (VLBWs) or small for gestational age (SGA). Maternal CMV serostatus was determined, and chart review and parental interviews were completed. Neonatal urine and throat cultures, and polymerase chain reaction (PCR) were performed. Dried blood spots (DBS) were tested for CMV by PCR.

RESULTS: In total, 213 infants were eligible for the study. Of these, 137 entered the study (79 VLBW and 58 SGA). Some families were not contacted for participation in the study due to neonatal deaths or early discharge. The mean age of the mothers was 27.6 years; $68 \%$ of the mothers were Caucasian and $16 \%$ were Aboriginal. The maternal CMV seroprevalence was $55 \%$. Seropositivity was significantly associated with ethnicity (First Nations [100\%]; Caucasian [34\%]) and country of birth (outside Canada [94\%]; Canadian born [45\%]). The rate of cCMV was two in $137(1.5 \%)$, with a rate of one in $79(1.3 \%)$ for the VLBW infants and one in $58(1.7 \%)$ for the SGA infants. Both had positive throat or urine specimens, but only the symptomatic infant was positive on DBS.

CONCLUSIONS: A cCMV screening program should be universal and routine to successfully screen all newborns. Maternal CMV seropositivity varies widely within the Canadian population. In the present pilot study, DBS PCR was not a sensitive screening tool and throat swab was the best screening specimen.

Key Words: Congenital; Cytomegalovirus; High-risk infants; Maternal seropositivity

$\mathrm{C}$ ongenital cytomegalovirus (cCMV) is the most common congenital infection, affecting $0.09 \%$ to $2.4 \%$ of all live births (1-4). This infection has devastating consequences both in the newborn period and later in life, including the late development of sensorineural hearing loss $(2,5-14)$. cCMV is a difficult diagnosis to prove retrospectively because definitive diagnosis requires isolation of CMV from the newborn within the first three weeks of life. Infection diagnosed beyond that age may indicate acquired infection (1). Although cCMV infection is usually asymptomatic and undiagnosed at birth, its

\section{Infection congénitale à cytomégalovirus chez des nourrissons canadiens à haut risque : Rapport d'une étude pilote de dépistage}

OBJECTIFS : L'infection congénitale à cytomégalovirus (cCMV) est la plus courante des infections congénitales. Toutefois, au Canada, l'épidémiologie de la maladie n'a pas récemment fait l'objet d'analyse. La présente recherche prospective testait des outils pour une étude de population sur l'infection à cCMV au Canada, en déterminant la séroprévalence et les facteurs de risque maternels, les caractéristiques cliniques et l'incidence de l'infection à cCMV à l'aide de diverses épreuves diagnostiques auprès d'une cohorte de nourrissons à risque élevé du Nord de l'Alberta.

MÉTHODES : Tous les nourrissons nés au Royal Alexandra Hospital d'Edmonton, en Alberta, entre le $1^{\text {er }}$ juin 2003 et le 31 mai 2004 ont été sélectionnés en vue de l'étude. Les nourrissons admissibles présentaient un très faible poids à la naissance (TFPN) et étaient petits pour leur âge gestationnel (PAG). Le statut des mères à l'égard du CMV a été déterminé et on a procédé à un examen des dossiers et à des entrevues avec les parents. On a également procédé à des cultures d'urine et de gorge et à des tests RCP (réaction en chaîne de la polymérase) chez les nouveau-nés. On a également procédé au dépistage du CMV par RCP sur du sang séché. RÉSULTATS : En tout, 213 nourrissons étaient admissibles à l'étude. Parmi eux, 137 y ont été inscrits (79 TFPN et 58 PAG). Certaines familles n'ont pas été contactées pour participer à l'étude en raison de mortalité néonatale ou de congé hâtif. Lâage moyen des mères était de 27,6 ans; 68 \% des mères étaient de race blanche et $16 \%$, d'origine autochtone. La séroprévalence du CMV maternel était de $55 \%$. La séropositivité a été significativement associée à l'ethnicité (Premières Nations [100 \%], race blanche [34 \%] et pays d'origine autre que le Canada [94 \%], nés au Canada [45 \%]). Le taux de cCMV était de deux sur 137 (1,5\%), avec un taux de un sur $79(1,3 \%)$ chez les nourrissons TFPN et de un sur $58(1,7 \%)$ chez les nourrissons PAG. Les deux présentaient des résultats positifs aux analyses de gorge et d'urine, mais seul le nourrisson symptomatique a obtenu des résultats positifs au test sur sang séché.

CONCLUSIONS : Le programme de dépistage du cCMV devrait être universel et appliqué d'emblée à tous les nouveau-nés pour être efficace. La séropositivité maternelle à l'égard du CMV varie beaucoup au sein de la population canadienne. Lors de la présente étude pilote, le test RCP sur sang séché ne s'est pas révélé être un outil de dépistage sensible et les échantillons de gorge ont été les plus propices à un dépistage efficace.

cumulative effect on the neurodevelopment of children is of great public health significance (5-11).

The rate of cCMV infection varies with the socioeconomic characteristics of a population and maternal CMV seroprevalence. Studies (14-25) from many countries as well as two recent reviews $(26,27)$ of universal newborn screening programs continue to underscore some variability among population groups as well as the universal significance of this infection in the long-term neurological outcome of children. Previous Canadian studies identified cCMV infection rates of $0.44 \%$ (25)

\footnotetext{
${ }^{1}$ Department of Pediatrics, University of Alberta; ${ }^{2}$ Provincial Laboratory for Public Health (Microbiology), Edmonton, Alberta

Correspondence: Dr Wendy Vaudry, Department of Pediatrics, University of Alberta, 8227 Aberhart Centre, Edmonton, Alberta T6G 2J3.

Telephone 780-407-1680, e-mail wendyvaudry@cha.ab.ca
} 
and $0.55 \%$ (28). Because social factors such as day care usage, breastfeeding practices, family size and immigration patterns may influence the incidence of CMV infection, the seroprevalence in women of childbearing age may have changed over time $(29,30)$. In addition, in a geographically large and socially diverse country such as Canada, it cannot be assumed that data generated from one part of the country can be extrapolated to another geographical area. Although cCMV infection is known to affect fetal growth, there is limited information on the rate of infection in infants of low birth weight. $(14,19)$. Current incidence data derived from specific populations are critical in planning targeted intervention strategies. Molecular diagnostic techniques (polymerase chain reaction [PCR]) have been developed which may improve the logistics of screening large populations of newborn infants (31-33). These assays have been performed on saliva, urine and dried blood spots (DBS) routinely collected for neonatal metabolic screening. The use of DBS has been recommended as a sensitive and convenient method for routinely screening large populations of infants (34), while other groups have recommended using throat swab (3).

There is a need for cCMV screening programs for several reasons. Intervention strategies are increasingly available (30). The advantages of diagnosing hearing loss early in infancy and early childhood have been well documented (35), and universal newborn hearing screening has been recommended by the National Institutes of Health (USA) (31). However, screening in the newborn period would miss more than one-half of the cases of sensorineural hearing loss caused by cCMV (36). Also, there is evidence that antiviral therapy with ganciclovir in neonates with neurological manifestations of cCMV infection improves hearing outcome (37), and further studies are being initiated to assess longer-term therapy with oral antiviral agents.

The ultimate solution for cCMV disease is prevention of infection. An immunization program, analogous to the congenital rubella success story, would be ideal (38). To that end, vaccines are being developed and some have been assessed in clinical trials (39) with the CMV glycoprotein B vaccine showing 50\% efficacy to prevent infection (40). While awaiting the successful development of vaccines, educating pregnant women about how to avoid infection has been proposed $(3,41,42)$.

In the present study, tools for a prospective cCMV screening program were evaluated in a high-risk group of newborns in northern Alberta. While this population may not be representative of the population as a whole, this high-risk group was selected to limit the number of subjects in the pilot study while at the same time targeting a cohort which was expected to have a higher incidence of cCMV. The maternal seroprevalence and risk factors for CMV serostatus were determined. The feasibility and validity of a standardized questionnaire, case report form, collection of specimens and use of various laboratory screening tools were assessed. The incidence of cCMV infection was determined for this high-risk group of Canadian infants.

\section{METHODS}

\section{Study setting}

The study was conducted from June 1, 2003, to May 31, 2004, at the Royal Alexandra Hospital (RAH) in Edmonton,
Alberta. The hospital provides perinatal care to the city of Edmonton and is the sole provider of tertiary level neonatal intensive care to the entire population of northern Alberta and much of the western Arctic. All newborns admitted to this hospital were screened for the study.

\section{Eligibility criteria}

To be eligible for the study, infants had to be 14 days of age or younger, expected to survive more than $24 \mathrm{~h}$, and meet the inclusion criteria for one of three categories of high-risk infants: infants of very low birth weight (VLBW) who were $1250 \mathrm{~g}$ at birth or less; infants who were small for gestational age (SGA) with a birth weight at the third percentile or lower; and infants with severe or life-threatening respiratory failure defined as requiring high-frequency ventilation or with an oxygenation index of 25 or greater. These groups of infants were considered to be at potentially higher risk of either cCMV or hearing loss. After informed written consent was obtained from the parent or guardian of each participant, the study procedures were undertaken. A separate maternal consent was obtained for testing frozen maternal sera collected as part of the routine prenatal screening in early pregnancy. The study was approved by the Health Research Ethics Board of the University of Alberta (Edmonton, Alberta).

\section{Screening methods}

Recruitment and clinical: All infants admitted to all of the RAH newborn nurseries (level III neonatal intensive care unit, level II nurseries and normal newborn nursery) were screened. Infants fulfilling the entry criteria were identified from the admission lists, and the parent or legal guardian was approached by neonatal research nurses during weekday normal working hours. A log was maintained to account for all eligible patients and document the reasons for nonparticipation in the study. The study nurse completed a case report form using a combination of a newly developed parent interview questionnaire and chart review.

Epidemiologic and demographic assessment: Data on risk factors associated with maternal serostatus or cCMV infection such as maternal age, parity, ethnicity, country of birth, urban or rural residence (as determined by the second digit of the postal code), educational and income level, occupation, number and age of household contacts and day care exposure were collected. Information obtained by both the interview and chart review was compared to assess the reliability of the interview questionnaire. Comparisons were made between the SGA and VLBW infant groups and between the CMV seropositive and seronegative mothers.

Laboratory assessment: Maternal serology - testing for CMV immunoglobulin G (IgG) antibody (Enzygnost anti-CMV IgG, Dade Behring, USA) was performed according to the manufacturer product insert at the conclusion of the study.

Neonatal virology - Specimens for the study were collected within the first 14 days of life and submitted to the Provincial Laboratory for Public Health (Edmonton, Alberta) using a special study requisition. The throat swabs were collected in M5 viral transport media (M5, Remel Products, USA) and the urine specimens were collected in a sterile container. The specimens were processed for CMV shell vial culture according to routine diagnostic procedures (Merifluor CMV, Meridian Bioscience Inc, USA) and aliquots were frozen at $-70^{\circ} \mathrm{C}$ for 
PCR testing at the end of the study period (see PCR method). Results of CMV shell vial cultures were reported to the clinicians as soon as they were available. Infants identified as CMV infected were investigated for the manifestations of cCMV disease including cranial computed tomography scan, audiology and ophthalmology assessments, complete blood count and liver function tests. Many of the infants also received these investigations as part of the routine care for high-risk infants and all the results were collected to assess the feasibility of the case report form. Neurodevelopmental follow-up was provided for all CMV-positive infants by the Glenrose Rehabilitation Hospital Neonatal and Infant follow-up clinic and audiology department in Edmonton, Alberta. The Glenrose clinic and the infants' community pediatricians were also consulted to obtain the long-term follow-up after one year.

On a monthly basis, the list of infants identified as study participants was provided to the provincial metabolic screening unit so that one of the DBS collected on filter paper as part of routine neonatal metabolic screening could be saved for PCR testing. The pathology department was monitored for autopsy findings consistent with cCMV infection on infants greater than 22 weeks' gestation (live or stillborn) during the study period.

PCR method - Two hundred microlitres of the stored urine sample was used for DNA extraction using a Qiagen DNA mini kit (Qiagen Inc, Canada) according to the manufacturer's protocol. DNA was eluted from the column with $50 \mathrm{~mL}$ of distilled water. Similarly, $200 \mu \mathrm{L}$ of the stored M5 viral transport media for the throat swab was used in the Qiagen extraction. Each blood spot was incubated at room temperature for $30 \mathrm{~min}$, with brief vortex every $5 \mathrm{~min}$ to $10 \mathrm{~min}$ in $300 \mu \mathrm{L}$ TE buffer containing $10 \mathrm{mM}$ Tris HCL and $1 \mathrm{mM}$ EDTA at $\mathrm{pH}$ 8.0. Proteinase $\mathrm{K}$ digestion was performed at $56^{\circ} \mathrm{C}$ for 10 min after the addition of $200 \mu \mathrm{L}$ of lysis buffer which contained $9 \mathrm{M}$ guanidine thiocyanate, $100 \mathrm{mM}$ Tris- $\mathrm{HCl}$, 2.8\% Triton X-100 and 50 mM EDTA. Nucleic acid extraction of the solution was performed using MagaZorb DNA extraction kit (Cortex Biochem, USA) according to the manufacturer's instructions. Laboratory-developed CMV DNA PCR (CMV LC-PCR) was performed on the LightCycler (Roche Diagnostics, USA) using primers gpB1 and gpB2 of the CMV glycoprotein B gene with an expected 254 base pair product as previously described (43). The limit of detection of the CMV LC-PCR is one copy per PCR reaction with accurate quantitation when there are 10 copies per PCR reaction. The hybridization donor probe with a fluorescein 3 ' end label and the acceptor probe with an LC-Red 640 5' end label were used for real-time detection during the CMV LC-PCR. Briefly, $5 \mu \mathrm{L}$ of DNA extracted from either the throat swab, urine or DBS were put in a PCR reaction mixture containing $4 \mathrm{mM}$ magnesium chloride, $0.5 \mathrm{mM}$ of each primer, $0.2 \mathrm{mM}$ of each probe and $2 \mu \mathrm{L}$ of the reagent from a LC-FastStart DNA Master hybridization probe kit (Roche Diagnostics, USA) and added to the capillaries. Positive and negative controls were included in each PCR run. For data analysis, baseline adjustment was performed in the arithmetic mode of the LC software, version 3. Positive specimens were defined by a fluorescence signal that was higher than the background. The CMV copy number per PCR reaction was calculated based on the crossing thresholds of positive samples compared with crossing thresholds of serially diluted CMV plasmid standards. For samples that were tested negative with the CMV LC-PCR, DNA extracted from CMV-infected MRC cells were added to the samples and the LC-PCR repeated. The presence of inhibitors was detected by a negative result of the second LC-PCR.

\section{Data analysis}

Frequencies were calculated for categorical data, and $\chi^{2}$ tests or the Fisher's exact test compared the study groups. Some categories were combined from the original questionnaire (eg, employment status categories were combined into employed outside the home or not). Proportions were calculated for key outcomes. Successful collection rates for each specimen type were calculated as proportions of the total subjects. The incidence rate of cCMV was determined by calculating the proportion of patients entered in the study who had a positive CMV culture. Continuous data were presented as mean $\pm \mathrm{SD}$ or median and range depending on the skewness of the data. Two sample $t$ tests and Wilcoxon's rank sum tests were used to compare group means or medians, respectively. Multivariable analyses were not performed because of the small numbers of infected infants.

Missing and incomplete data were investigated. The number of eligible infants who were not tested was determined and the reasons were documented. The number of specimens collected from each study subject was recorded. The reasons for not collecting specimens or difficulty collecting specimens were documented. The time required to complete the protocol for each candidate was also recorded. Cases with discrepancies between PCR results and urine shell vial culture were investigated with follow-up viral cultures, prenatal serology on the mothers and outcome data on the infants affected. A P $<0.05$ was considered to be statistically significant. SPSS (SPSS Inc, USA) and S-Plus (S-Plus 7.0 for Windows, Insightful Corporation, 2005) were used for analyses.

\section{Recruitment and clinical}

\section{RESULTS}

There were a total of 213 infants from the three inclusion groups eligible for the study; Table 1 accounts for all eligible infants and compares the birth weights and gestational ages of these groups. Because there were only four infants in the respiratory failure group, with a mean birth weight of $1584 \mathrm{~g}$, and their inclusion did not change the results, they are included with the VLBW infants in subsequent analyses. Overall, the parents of 179 (84\%) infants were contacted and 137 (77\% of those contacted) gave their consent. The primary reasons families were not contacted for participation in the study were neonatal death (7\%) for VLBW infants and discharge from hospital before families could be contacted (18\%) for SGA infants. For the SGA infants, the gestational age and birth weight of the infants who were contacted were significantly lower than those who were not. There was no evidence of a statistically significant difference in gestational age and birth weight for those who consented and those who did not.

The incidence of jaundice, anemia and thrombocytopenia was higher in the VLBW infants than the SGA infants. However, anemia developed earlier in the SGA infants, suggesting that the abnormality in this group was less likely to be 
TABLE 1

Congenital cytomegalovirus screening recruitment: Eligible patient outcome and clinical characteristics

\begin{tabular}{|c|c|c|c|c|c|c|}
\hline \multirow{2}{*}{$\begin{array}{l}\text { Eligible, n (\%) } \\
\text { Contacted }\end{array}$} & \multicolumn{2}{|c|}{ VLBW } & \multicolumn{2}{|c|}{ SGA } & \multicolumn{2}{|c|}{ Total } \\
\hline & \multicolumn{2}{|c|}{$118(55)$} & \multicolumn{2}{|c|}{$95(45)$} & \multicolumn{2}{|c|}{$213(100)$} \\
\hline n (\%) & 105 (89) & $13(11)$ & $74(78)$ & $21(22)$ & $179(84)$ & $34(16)$ \\
\hline Gestational age, weeks & $27.4 \pm 2.7$ & $26.0 \pm 1.7$ & $38.3 \pm 1.6$ & $39.3 \pm 0.9^{\star}$ & - & - \\
\hline Consented & Yes & No & Yes & No & Yes & No \\
\hline n (\%) & $79(75)$ & $26(25)$ & $58(78)$ & $16(22)$ & $137(77)$ & $42(24)$ \\
\hline Gestational age, weeks & $27.3 \pm 2.5$ & $27.8 \pm 3.3$ & $38.3 \pm 1.7$ & $38.4 \pm 1.6$ & - & - \\
\hline
\end{tabular}

Data presented as mean \pm SD unless otherwise stated. *Statistically significant difference at $P<0.05$. SGA Small for gestational age; VLBW Very low birth weight

iatrogenic and more likely to be congenital. There were no infants in either group described with hepatomegaly or splenomegaly; only three infants had a rash. Three infants had congenital anomalies consisting of one each of hypospadias, tetralogy of Fallot, and cleft lip and palate.

\section{Epidemiological and demographic}

All of the clinical details of the cases with positive CMV testing results were effectively captured by the case report form, and no additional retrospective chart review was required to describe the initial case presentations. A parent interview and chart review was completed for all study participants. For 130 of the 137 infants, the date of birth recorded at the interview agreed with the date of birth entered from the chart review. For three infants, the information was not recorded at the interview, two were discordant by one day, one was discordant for two days and one was discordant for 61 days. The time of birth was consistent between the interview and chart review for 112 of 137 infants. For three infants, the time was not recorded; for 22 , the time of birth was discordant. The mean discrepancies for 21 cases was $5.3 \mathrm{~min}$; one interview reported the time of birth as different by almost $22 \mathrm{~h}$. The interviews were easy to administer and complete, and required approximately $10 \mathrm{~min}$ to perform. There were 128 interviews conducted for 137 study subjects because there were multiple births accounting for 19 infants being born to nine mothers (eight sets of twins, one set of triplets). The respondent was the mother for 81 infants, the father for six, both mother and father for 36, and other caregiver for two.

The demographic data were compared for the SGA and VLBW groups. There was no evidence of a statistical difference between the groups for the variables assessed and the whole study group $(n=128)$ of high-risk infants is summarized together. The mean age of the mothers was 27.6 years (range 15.7 to 45.1 years) and 30.2 years for the fathers (range 17.1 to 50.2 years). The majority of mothers ( 85 of $125 ; 68 \%$ ) were Caucasian and $20(16 \%)$ were Aboriginal (including First Nations). Of mothers, $33(26 \%, n=125)$ had only completed primary school, 50 (40\%) had completed high school and the remaining 42 (34\%) had completed some form of postsecondary education. Married mothers numbered $54(43 \%, n=125)$; $42(34 \%)$ were living common law. The majority of mothers $(74,59 \%, n=125)$ were engaged in full or part-time employment outside the home, and five mothers were employed in child day care. For the fathers, a variety of other employment was recorded and no clustering of any one particular job was observed. Household income was reported for 106 of the infants.

The study group as a whole (SGA and VLBW together) was then analyzed for risk factors for maternal CMV seropositivity. Six mothers (two of VLBW and four of SGA infants) had missing serology results. Therefore, results on 121 mothers were available for analysis; $55 \%$ of the mothers were CMV seropostive. The demographic characteristics of the seropositive and seronegative mothers are compared in Table 2 . The results are presented as either continuous or discrete variables. For discrete variables, the count (percentage of the total for the variable) is presented; for continuous variables, the mean \pm SD is presented. There was no evidence of a difference in any of the continuous variables measured. There was evidence of a difference in maternal parity with the number of abortions being higher for the seronegative group $(\mathrm{P}<0.05)$, and the number of live births $(\mathrm{P}<0.05)$ and household exposure to young children $(\mathrm{P}<0.05)$ being higher in the seropositive group. The identification of the mother's type of employment was quite variable with 60 different responses; therefore, these responses were not compared statistically. They were assessed qualitatively by the investigators and no clustering of type of employment was identified. Specifically, the number of mothers employed in the child day care setting was not different between the seropositive and seronegative groups.

The most significant associations with maternal seropositivity were maternal ethnicity with First Nations mothers having a seroprevalence of $100 \%$, mothers of other Aboriginal status $67 \%$, Asian mothers 100\%, black mothers 100\% and Caucasian mothers $34 \%(\mathrm{P}<0.05)$. Country of birth was also significantly associated, with $45 \%$ of mothers born in Canada and $94 \%$ of mothers born outside of Canada being seropositive for CMV $(\mathrm{P}<0.05)$. Canadian-born Caucasian mothers had a seropositivity rate of $33 \%$ (27 of 81$)$.

\section{Laboratory results}

Neonatal virology and PCR: Throat swab was the most reliably collected specimen on all infants. It was successfully collected and processed for viral culture in 130 of 137 infants. The reason given in two of the cases for the throat swab not being collected was parental refusal. Urine for viral culture was collected and processed in 111 of 137 infants and was successfully collected less often for SGA infants. The commonest reason given for not collecting the urine was that the infant was discharged before the specimen could be collected. Most patients (97\%) had a throat and/or urine specimen collected (77 of 
TABLE 2

Characteristics of mothers* seropositive and seronegative for cytomegalovirus

\begin{tabular}{|c|c|c|c|}
\hline & Seronegative & Seropositive & Tota \\
\hline Total, n (\%) & $57(45)$ & $64(55)$ & 121 \\
\hline Age, years (mean $\pm S D$ ) & $27.7 \pm 6.14$ & $27.9 \pm 6.83$ & - \\
\hline Rural residence & $11(41)$ & $16(59)$ & 27 \\
\hline \multicolumn{4}{|l|}{ Ethnicity ${ }^{\dagger}$} \\
\hline Caucasian & $55(66)$ & $28(34)$ & 83 \\
\hline First Nations & $0(0)$ & $16(100)$ & 16 \\
\hline Black & $0(0)$ & $2(100)$ & 2 \\
\hline Aboriginal (other) & $1(33)$ & $2(67)$ & 3 \\
\hline Asian & $0(0)$ & $11(100)$ & 11 \\
\hline Other & $1(20)$ & $4(80)$ & 5 \\
\hline Missing & - & 1 & 1 \\
\hline \multicolumn{4}{|l|}{ Country of birth ${ }^{\dagger}$} \\
\hline Canada & $56(55)$ & $46(45)$ & 102 \\
\hline Other & $1(6)$ & $17(94)$ & 18 \\
\hline Missing & - & 1 & 1 \\
\hline \multicolumn{4}{|c|}{ Highest level of education completed, n (\%) } \\
\hline Primary school & $11(37)$ & $19(63)$ & 30 \\
\hline High school & $24(50)$ & $24(50)$ & 48 \\
\hline Community/Technical & $11(61)$ & 7 (39) & 18 \\
\hline University & $10(56)$ & $8(44)$ & 18 \\
\hline Degree/Grad & $1(17)$ & $5(83)$ & 6 \\
\hline Missing & - & 1 & 1 \\
\hline \multicolumn{4}{|l|}{ Marital status } \\
\hline Married & $25(49)$ & $26(51)$ & 51 \\
\hline Single & $11(46)$ & $13(54)$ & 24 \\
\hline Separated & $2(67)$ & $1(33)$ & 3 \\
\hline Common Law & $19(45)$ & $23(54)$ & 42 \\
\hline Missing & - & 1 & 1 \\
\hline \multicolumn{4}{|l|}{ Employment } \\
\hline Employed outside the home & $43(52)$ & $40(48)$ & 83 \\
\hline $\begin{array}{l}\text { Not employed outside the } \\
\text { home }\end{array}$ & $14(38)$ & $23(62)$ & 37 \\
\hline Missing & - & 1 & 1 \\
\hline \multicolumn{4}{|l|}{ Lives with children $^{\dagger}$} \\
\hline Yes & $10(29)$ & $24(71)$ & 34 \\
\hline No & $47(55)$ & $39(45)$ & 86 \\
\hline Missing & - & 1 & 1 \\
\hline \multicolumn{4}{|l|}{ Number of gestations } \\
\hline 1 & $21(48)$ & $23(52)$ & 44 \\
\hline 2 & $15(44)$ & $19(56)$ & 34 \\
\hline 3 & $15(63)$ & $9(37)$ & 24 \\
\hline 4 & $2(33)$ & $4(67)$ & 6 \\
\hline$>4$ & $4(31)$ & $9(69)$ & 13 \\
\hline Mean \pm SD & $2.37 \pm 1.81$ & $2.42 \pm 1.6$ & - \\
\hline \multicolumn{4}{|l|}{ Parity number ${ }^{\dagger}$} \\
\hline 0 & $36(55)$ & $30(45)$ & 66 \\
\hline 1 & $14(42)$ & $19(58)$ & 33 \\
\hline 2 & $4(57)$ & $3(43)$ & 7 \\
\hline 3 & $1(17)$ & $5(83)$ & 6 \\
\hline 4 & $0(0)$ & $4(100)$ & 4 \\
\hline$>4$ & $2(40)$ & $3(60)$ & 5 \\
\hline \multicolumn{4}{|l|}{ Number of abortions ${ }^{\dagger}$} \\
\hline 0 & $33(43)$ & $43(57)$ & 76 \\
\hline 1 & $11(38)$ & $18(62)$ & 29 \\
\hline 2 & $10(77)$ & $3(23)$ & 13 \\
\hline 3 & $2(100)$ & $0(0)$ & 2 \\
\hline 4 & $1(100)$ & $0(0)$ & 1 \\
\hline
\end{tabular}

Data presented as $n$ (\%) unless otherwise stated. *Mothers with infants from both the small for gestational age and very low birth weight groups were combined for this analysis. ${ }^{\dagger}$ These variables were significant at the $P<0.05$ level
79 VLBW infants and 56 of 58 SGA infants) (Table 3). Not all specimens were tested by CMV LC-PCR because the specimens were not always identified as part of the study; thus, aliquots were not stored for testing at the end of the study and specimens could not be recollected at that time. Only 105 DBS specimens were retrieved from the metabolic screening centre and 95 of these were handled in a manner that would allow reliable PCR testing.

Four subjects had CMV-positive results, which are summarized in Table 3. Two infants tested positive by both culture and CMV LC-PCR. Case 1 was an SGA infant born to a Canadianborn 28-year-old woman of high socioeconomic status. The mother had a negative IgG and an indeterminate IgM to CMV at 12 weeks' gestation and was IgG and IgM positive to CMV at delivery, thus confirming a primary maternal infection with CMV during gestation. This infant was symptomatic with thrombocytopenia, abnormal cranial imaging and deafness in the newborn period and was positive for CMV on viral culture of urine and throat, LC-PCR positive from both urine and throat and LC-PCR positive on DBS. Case 2 was a VLBW infant born to a 42-year-old non-Canadian-born woman who was IgG positive to CMV at 10 weeks' gestation and likely had reactivation infection during gestation. The infant was asymptomatic for cCMV and remained normal developmentally and audiologically at one year of age. This infant was culture and LC-PCR positive from both urine and throat but was negative from the DBS. Two infants (case 3 [VLBW] and case 4 [SGA]) tested positive by CMV LC-PCR in various specimen types and were negative by culture. Both of these infants were asymptomatic for cCMV at birth and on follow-up after one year of age. Both infants were negative for CMV on viral culture of urine recollected after one year of age when results of PCR assays became available. Using the traditional gold standard of viral culture to define cCMV infection, the overall rate of infection was two of $137(1.5 \%)$, with a rate of one of $79(1.3 \%)$ for the VLBW infants and one of $58(1.7 \%)$ for the SGA infants.

\section{DISCUSSION}

The present study was designed as a feasibility pilot study for a future larger population-based screening for an entire birth cohort. Therefore, the outcomes of greatest interest were related to the development and feasibility assessment of the tools for such a study. In addition, the maternal seroprevalence and incidence of cCMV were determined for this high-risk group of newborns in a Canadian population.

The authors accounted for all infants eligible for the study. There was no evidence of a significant difference between the infants entered and not entered in the study, except for the birth weight of SGA infants. Larger, more mature, infants were discharged from the hospital sooner, often within $24 \mathrm{~h}$ of birth; therefore, the parents were less likely to be contacted to give informed consent. The difference in mean birth weight would not have likely affected the rate of CMV positivity in the tested subjects. However, this difference in contact rate provides important data documenting the difficulty of entering all infants into a hospital-based population screening study if parental contact is required. Low-risk term infants are typically discharged from hospital within $24 \mathrm{~h}$ of birth in Canada. If parental contact and consent were required, the screening would clearly be incomplete This finding supports the need for universal screening of all newborns to be routine. 


\begin{tabular}{|c|c|c|c|c|c|}
\hline \multirow[b]{3}{*}{ Specimen status } & \multicolumn{5}{|c|}{ Specimen collected } \\
\hline & \multicolumn{2}{|c|}{ Urine $(n=113)$} & \multicolumn{2}{|c|}{ Throat $(n=132)$} & \multirow{2}{*}{$\begin{array}{c}\text { DBS }(n=137) \\
\text { PCR }(n=95)\end{array}$} \\
\hline & Culture $(n=111)$ & PCR (n=91) & Culture $(n=130)$ & PCR $(n=116)$ & \\
\hline Positive & 2 & 3 & 2 & 3 & 2 \\
\hline Negative & 108 & 88 & 127 & 113 & 93 \\
\hline Toxic & 1 & NA & 1 & NA & NA \\
\hline \multicolumn{6}{|c|}{ Cases with positive results } \\
\hline Case 1 & Positive & $\begin{array}{l}\text { Positive } \\
4.8 \times 10^{5} \text { copies per } \\
\text { PCR reaction }\end{array}$ & Positive & $\begin{array}{l}\text { Positive } \\
9.5 \times 10^{4} \text { copies per } \\
\text { PCR reaction }\end{array}$ & $\begin{array}{l}\text { Positive } \\
180 \text { copies per } \\
\text { PCR reaction }\end{array}$ \\
\hline Case 2 & Positive & $\begin{array}{l}\text { Positive } \\
4.1 \times 10^{3} \text { copies per } \\
\text { PCR reaction }\end{array}$ & Positive & $\begin{array}{l}\text { Positive } \\
15 \text { copies per } \\
\text { PCR reaction }\end{array}$ & Negative \\
\hline Case 3 & Negative & $\begin{array}{l}\text { Positive } \\
10 \text { copies per } \\
\text { PCR reaction }\end{array}$ & Negative & $\begin{array}{l}\text { Positive } \\
120 \text { copies per } \\
\text { PCR reaction }\end{array}$ & Negative \\
\hline Case 4 & Not done & Not done & Negative & Negative & $\begin{array}{l}\text { Positive } \\
40 \text { copies per } \\
\text { PCR reaction }\end{array}$ \\
\hline
\end{tabular}

DBS Dried blood spot; NA Not applicable; PCR Polymerase chain reaction

The study describes the demographics of these high-risk infants for a Canadian population in northern Alberta using a newly developed questionnaire. Although this pilot study was too small to assess the statistical significance of demographic risk factors for cCMV infection, the association with maternal CMV seropositivity was investigated. The strongest evidence for an association with seropositivity was found for non-Caucasian ethnicity and birth outside of Canada, with almost $100 \%$ of mothers in these categories being seropositive for CMV. In contrast, only 33\% of Canadian-born Caucasian mothers were seropositive. There was no evidence of an association with other demographic factors previously associated with maternal CMV seropositivity such as younger maternal age and unmarried marital status. Factors such as household crowding, contact with young children both in the home and day care settings, and possible occupational risk factors such as work in a child day care centre have been associated with higher seroprevalence and seroconversion in the populations tested $(44,45)$. Even in this small pilot study, the association with household contact with young children and CMV seropositivity was suggested. These demographic risk factors have important implications in counselling pregnant women now and targeting future prevention programs. A study of an entire birth cohort would be necessary to characterize the full spectrum of risk factors, clinical manifestations and long-term sequelae of cCMV in Canada.

Ninety seven per cent (133 of 137) of the infants entered into the study had at least one specimen sent for viral culture. The throat swab was collected most frequently. The urine was collected less frequently and this was primarily for logistical reasons of ease and time of collection. As expected, the rate of cCMV infection in this small sample of high-risk infants was relatively high. The rate for VLBW infants likely represents a true population-based rate for this region of Canada because all VLBW infants for this geographical region would have been captured in the study. The rate of infection for SGA infants is less likely to be population based and may suffer from some referral bias. Most, but not all, SGA infants for the region would have been admitted to the RAH nurseries. However, this is the first time the rate of infection has been determined for these high-risk groups in Canada.

The two cases with positive CMV viral cultures are typical of primary and reactivation disease, respectively. Case 1 illustrates primary infection during pregnancy in a woman of high socioeconomic status who delayed primary infection until young adulthood. Her infant was symptomatic at birth and manifested neurodevelopmental sequelae on follow-up. The infant was viremic in the neonatal period as indicated by the positive PCR on DBS. Case 2 likely represents asymptomatic infection caused by CMV reactivation in a previously infected mother. This mother is older, multiparous and an immigrant from a country with higher endemic infection rates. Longerterm follow-up will be required to document the possible occurrence of late sequelae.

There were four infants with positive CMV results in the study. Two infants fulfilled the traditional gold standard of having positive CMV cultures. One of these two infants was symptomatic at birth and only the symptomatic infant also tested positive for CMV by PCR with DBS. This is consistent with previously reports that DBS screening may miss infants who are not viremic (46) or have a low viral load (47) at birth and are asymptomatic. A screening program which relies on initial DBS PCR testing followed by viral culture as has been proposed by others $(34,48)$ may not have adequate sensitivity or specificity. On the other hand, the two infants who tested positive only by CMV LC-PCR were asymptomatic, and one of them tested positive with DBS only. The amount of CMV virus in the specimens that were positive by CMV LC-PCR only was lower than in the specimens that were also culture positive (Table 3, cases 3 and 4) Although a false-positive PCR test is possible and has been considered as such by others in a screening program (3), it is unlikely to be the explanation for multiple positives from different specimens in the same infant. The quantitative CMV viral load in amniotic fluid was shown to be an important prognostic factor for making a prenatal diagnosis of cCMV (49,50). PCR assays across laboratories are not 
standardized. Defining a threshold of CMV viral load in urine and throat swabs that will correlate with clinically relevant cCMV infections would be important in the validation of PCR diagnostic assays.

The limitations of the study are primarily related to the small sample size, which was anticipated because it was a pilot study. The number of eligible study candidates who were not entered into the study because they were not contacted or did not consent would be unlikely to have affected the results; the groups were accounted for and compared for birth weight. The small sample size of high-risk infants may also mean that there were associations with risk factors for seropositivity that the study did not detect and the full spectrum of cCMV disease could not be described. Some of the specimens for PCR were not processed appropriately at the beginning of the study, but these logistical challenges were addressed early on and resolved to the extent that a useful volume of testing was ultimately performed.

\section{SUMMARY AND CONCLUSIONS}

The present study piloted the use of tools for a cCMV screening program in a population of high-risk newborns in Canada. The challenges of recruiting and collecting specimens from a variety of newborn populations were documented. The overall demographic characteristics, maternal CMV seroprevalence, risk factors for maternal CMV seropositivity and rate of cCMV infection were determined for this population.

The maternal seroprevalence for CMV varies widely, and the most important demographic risk factors for CMV seropositivity were non-Caucasian race and birth outside of Canada. The cCMV infection rate was $1.5 \%$ overall in this high-risk population. A cCMV screening program should be universal and routine to successfully screen all newborns, and the cost-effectiveness of such programs should be assessed in the Canadian context. Our experience suggests that DBS PCR is not an adequate screening tool; throat swab PCR may be the best screening specimen and the ideal testing methodology is still to be determined.

COMPETING INTERESTS: The authors declare no competing interests.

AUTHORS' CONTRIBUTIONS: WV conceived of, designed and oversaw the study and drafted the manuscript. RJR participated in the design of the study and led the statistical analysis. BEL contributed to the design of the study and analysis of the results and oversaw the laboratory procedures. PYC participated in the study design and oversaw patient recruitment. XLP carried out the PCR testing. JKP helped conceive of the study and participated in its design and coordination. All authors read and approved the final manuscript.

ACKNOWLEDGEMENTS: This research was supported by funding from the Stollery Children's Hospital Foundation (Edmonton, Alberta) and the Royal Alexandra Hospital Foundation (Edmonton, Alberta). Dr Rosychuk is supported as Population Health Investigator from the Alberta Heritage Foundation for Medical Research (Edmonton, Alberta). Dr Cheung is supported as a Clinical Investigator by the Alberta Heritage Foundation for Medical Research and the Canadian Institutes of Health Research (Ottawa, Ontario). The authors thank Barb Kamstra and the nurses of the Neonatal Research Laboratory at the Royal Alexandra Hospital for patient recruitment and data collection, the virology staff at the Provincial Laboratory (Edmonton, Alberta) for processing the specimens for cytomegalovirus shell vial culture and performing the cytomegalovirus immunoglobulin $G$ tests, and Christina Alloway from the Biostatistics Consulting Group at the University of Alberta for assistance with data analysis.

\section{REFERENCES}

1. Stagno S, Pass RF, Alford CA. Perinatal infections and maldevelopment. In: Bloom AD, James LS, eds. The Fetus and the Newborn. New York: Alan R Liss, 1981:31-50.

2. Weller TH, Hanshaw JB. Virologic and clinical observations on cytomegalic inclusion disease. N Engl J Med 1964;266:1233-44.

3. Gaytant MA, Galama JM, Semmekrot A, et al. The incidence of congenital cytomegalovirus infections in the Netherlands. J Med Virol 2005;76:71-5.

4. Istas AS, Demmler GJ, Dobbins JG, Stewart JA; the National Congenital Cytomegalovirus Disease Registry Collaborating Group. A report from the national congenital cytomegalovirus disease registry. Clin Infect Dis 1995;20:665-70.

5. McCracken GH, Shinefield HR, Cobb K, Rausen AR, Dische MR, Eichenwald HF. Congenital cytomegalic inclusion disease: A longitudinal study of 20 patients. Am J Dis Child 1969;117:522-39.

6. Berenberg W, Nankervis GA. Long-term follow-up of cytomegalic inclusion disease of infancy. Pediatrics 1970;46:403-10.

7. Kumar ML, Nankervis GA, Gold E. Inapparent congenital cytomegalovirus infection: A follow-up study. N Engl J Med 1973;288:1370-2.

8. Melish ME, Hanshaw JB. Congenital cytomegalovirus infection: Developmental progress of infants detected by routine screening. Am J Dis Child 1973;126:190-4.

9. Reynolds DW, Stagno S, Stubbs KG, et al. Inapparent congenital cytomegalovirus infection with elevated cord IgM levels: Causal relation with auditory and mental deficiency. $\mathrm{N}$ Engl J Med 1974;290:291-6.

10. Hanshaw JB, Scheiner AP, Moxley AW, Gaev L, Abel V, Scheiner B. School failure and deafness after "silent" congenital cytomegalovirus infection. N Engl J Med 1976;295:468-70.

11. Pass RF, Stagno S, Myers GJ, Alford CA. Outcome of symptomatic congenital cytomegalovirus infection: Results of long-term longitudinal follow-up. Pediatrics 1980;66:758-62.

12. Fowler KB, McCollister FP, Dahle AJ, Boppana S, Britt WJ, Pass RF. Progressive and fluctuating sensorineural hearing loss in children with asymptomatic congenital cytomegalovirus infection. J Pediatr 1997;130:624-30.

13. Fowler KB, Boppana SB. Congenital cytomegalovirus (CMV) infection and hearing deficit. J Clin Virol 2006;35:226-31.

14. Yamamoto AY, Mussi-Pinhata MM, Pinto PC, Figueiredo LT, Jorge SM. Congenital cytomegalovirus infection in preterm and full-term newborn infants from population with a high seroprevalence rate. Pediatr Infect Dis J 2001;20:188-92.

15. Halwachs-Baumann G, Genser B, Danda M, et al. Screening and diagnosis of congenital cytomegalovirus infection, a 5-year study. Scand J Infect Dis 2000;32:137-42.

16. Ahlfors K, Ivarsson SA, Harris S. Report on a long-term study of maternal and congenital cytomegalovirus infection in Sweden. Review of prospective studies available in the literature. Scan J Infect Dis 1999;31:443-57.

17. Engman ML, Malm G, Engstrom L, et al. Congenital CMV infection: Prevalence in newborns and the impact on hearing deficit. Scand J Infect Dis 2008;40:935-42.

18. Barbi M, Binda S, Primache V, Clerici D. Congenital cytomegalovirus infection in a northern Italian regional NEOCMV group. Eur J Epidemiol 1998;14:791-6.

19. Panhani S, Heinonen KM. Screening for congenital cytomegalovirus infection among preterm infants born before the 30th gestational week in Finland. Scand J Infect Dis 1994;26:375-8. 
20. Tsai CH, Tsai FJ, Shih YT, Wu SF, Liu SC, Tseng YH. Detection of congenital cytomegalovirus infection in Chinese newborn infants using polymerase chain reaction. Acta Paediatr 1996;85:1241-3.

21. Griffiths PD, Baboonian C. A prospective study of primary cytomegalovirus infection during pregnancy: Final report. Br J Obstet Gynaecol 1984;91:307-15.

22. Kamada M, Komori A, Chiba S, Nakao T. A prospective study of congenital cytomegalovirus infection in Japan. Scand J Infect Dis 1983;15:227-32.

23. Naessens A, Casteels A, Decatte L, Foulon W. A serologic strategy for detecting neonates at risk for congenital cytomegalovirus infection. J Pediatr 2005;146:194-7.

24. Distefano AL, Alonso A, Martin F, Pardon F. Human cytomegalovirus: Detection of congenital and perinatal infection in Argentina. BMC Pediatr 2004;4:11.

25. Larke RP, Wheatley E, Saigal S, Chernesky MA. Congenital cytomegalovirus infection in an urban Canadian community. J Infect Dis 1980;142:647-53.

26. Dollard SC, Grosse SD, Ross DS. New estimates of the prevalence of neurological and sensory sequelae and mortality associated with congenital cytomegalovirus infection. Rev Med Virol 2007;17:355-63.

27. Kenneson A, Cannon MJ. Review and meta-analysis of the epidemiology of congenital cytomegalovirus (CMV) infection. Rev Med Virol 2007;17:253-76.

28. Embil JA, MacDonald JM, Scott KE. Survey of a neonatal population for the prevalence of cytomegalovirus. Scand J Infect Dis 1975;7:165-7.

29. Yow MD. Congenital cytomegalovirus disease: A NOW problem. J Infect Dis 1989;159:163-7.

30. Adler SP, Nigro G, Pereira L. Recent advances in the prevention and treatment of congenital cytomegalovirus infections. Semin Perinatol 2007;31:10-8.

31. NIH Consensus Statement. Early identification of hearing impairment in infants and young children. The National Institutes of Health 1993;11:1-24

32. Johansson JH, Jonsson M, Ahlfors K, Ivarsson S, Svanberg L, Guthenberg C. Retrospective diagnostics of congenital cytomegalovirus infection performed by polymerase chain reaction in blood stored on filter paper. Scand J Infect Dis 1997;29:465-68.

33. Schaade L, Kockelkorn P, Ritter K, Kleines M. Detection of cytomegalovirus DNA in human specimens by lightcycler PCR. J Clin Microbiol 2000;38:4006-9.

34. Barbi M, Binda S, Caroppo S, et al. Multicity Italian study of congenital cytomegalovirus infection. Pediatr Infect Dis J 2006;25:156-9.

35. Kennedy CR, McCann DC, Campbell MJ, et al. Language ability after early detection of permanent childhood hearing impairment. N Engl J Med 2006;354:2131-64.
36. Fowler KB, Dahle AJ, Boppana SB, Pass RF. Newborn hearing screening: Will children with hearing loss caused by congenital cytomegalovirus infection be missed? J Pediatr 1999;135:60-4.

37. Kimberlin DW, Lin C-Y, Sanchez P, et al, for the NIAID and CASG. Effect of ganciclovir therapy on hearing in symptomatic congenital cytomegalovirus disease involving the central nervous system: A ramdomized controlled trial. J Pediatr 2003;143:16-25.

38. Yow MD, Demmler GJ. Congenital cytomegalovirus disease 20 years is long enough. N Engl J Med 1992;326:702-3.

39. Plotkin SA. Vaccination against cytomegalovirus. Arch Virol Suppl 2001;17:121-34.

40. Pass RF, Zhang C, Evans A, et al. Vaccine prevention of maternal cytomegalovirus infection. N Engl J Med 2009;360:1250-2.

41. Leon J, Victor M, Adler SP, et al. Knowledge and awareness of congenital cytomegalovirus infection among women. Infect Dis Obstet Gynecol 2006;14:80-3.

42. Cannon MJ, Davis KF. Washing our hands of the congenital cytomegalovirus disease epidemic. BMC Public Health 2005;5:70.

43. Pang XL, Chui L, Fenton J, LeBlanc B, Preiksaitis JK. Comparison of LightCycler-based PCR, COBAS amplicor CMV monitor, and pp65 antigenemia assays for quantitative measurement of cytomegalovirus viral load in peripheral blood specimens from patients after solid organ transplantation. J Clin Microbiol 2003;41:3167-74.

44. Joseph SA, Beliveau C, Muecke CJ, et al. Risk factors for cytomegalovirus seropositivity in a population of day care educators in Montreal, Canada. Occup Med (Lond) 2005;55:564-7.

45. Kenneson A, Cannon MJ. Review and met-analysis of the epidemiology of congenital cytomegalovirus infection. Rev Med Virol 2007; 17:253-76.

46. Bradfore RD, Cloud G, Lakeman AD, National Institute of Allergy and Infectious Diseases Collaborative Antiviral Study Group. Detection of cytomegalovirus (CMV) DNA by polymerase chain reaction is associated with hearing loss in newborns with symptomatic congenital CMV infection involving the central nervous system. J Infect Dis 2005;191:227-33.

47. Lanari M, Lazzarotto T, Venturi V. Neonatal cytomegalovirus blood load and risk of sequelae in symptomatic and asymptomatic congenitally infected newborns. Pediatrics 2006;117:e76-83.

48. Barbi M, Binda S, Caroppo S, Primache V. Neonatal screening for congenital cytomegalovirus infection and hearing loss. J Clin Virol 2006;35:206-9.

49. Fowler SL. A light in the darkness: Predicting outcomes for congenital cytomegalovirus infections. J Pediatr 2000;137:4-6.

50. Lazzarotto T, Varani S, Guerra B, Nicolosi A, Lanari M, Landini MP. Prenatal indicators of congenital cytomegalovirus infection. J Pediatr 2000;137:90-5. 


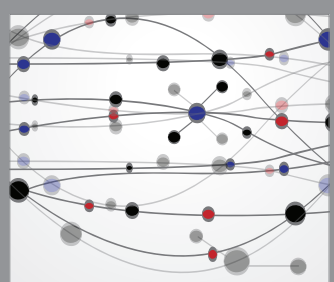

The Scientific World Journal
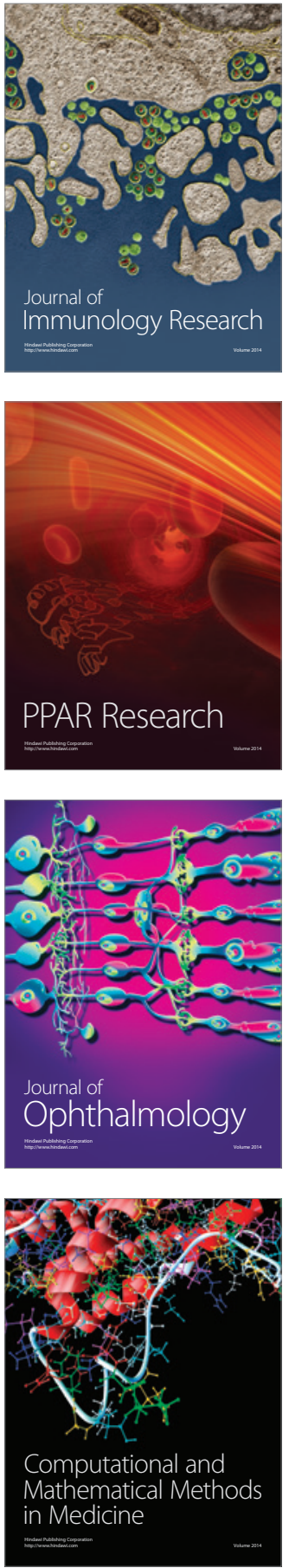

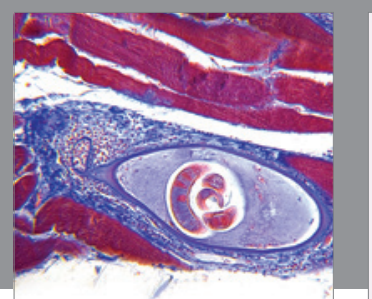

Gastroenterology Research and Practice

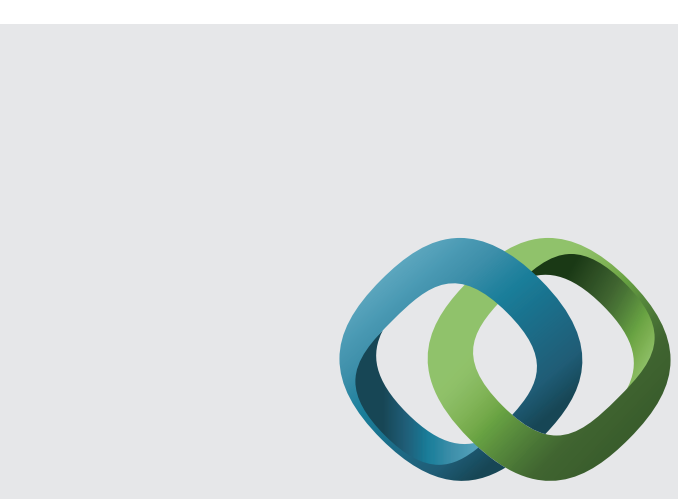

\section{Hindawi}

Submit your manuscripts at

http://www.hindawi.com
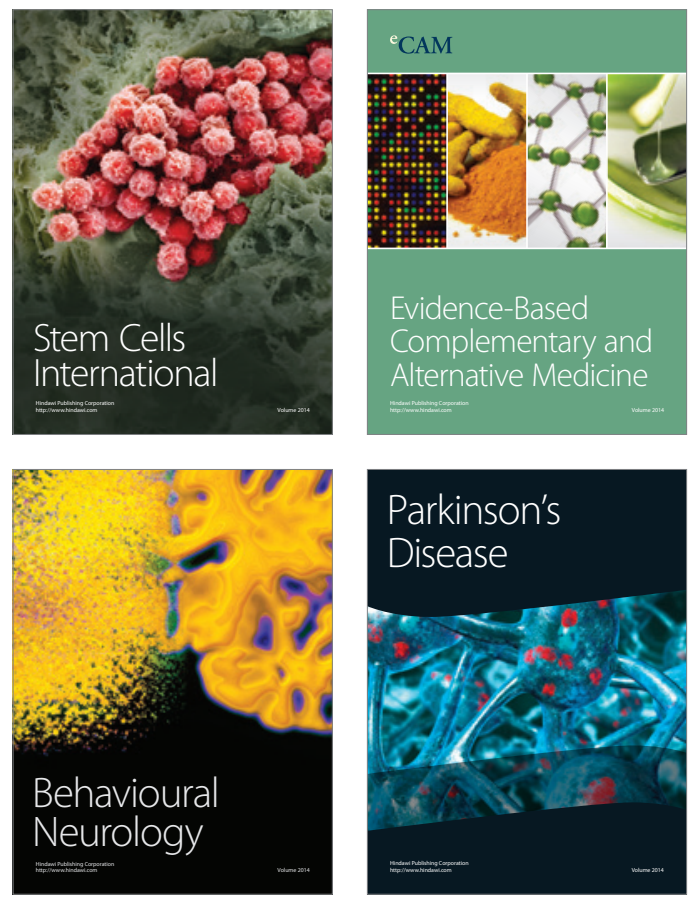
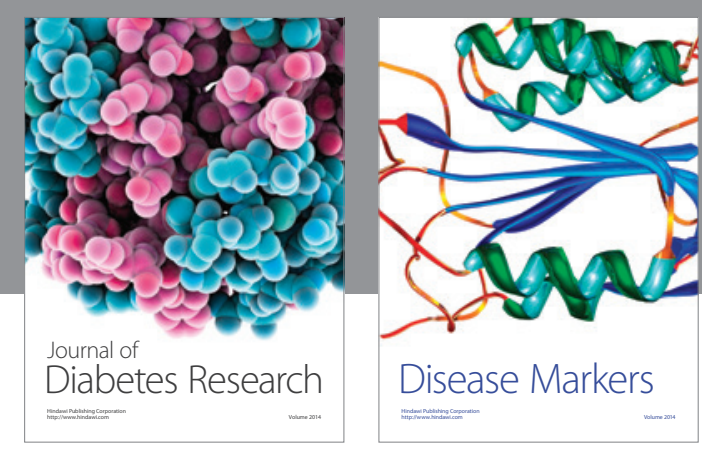

Disease Markers
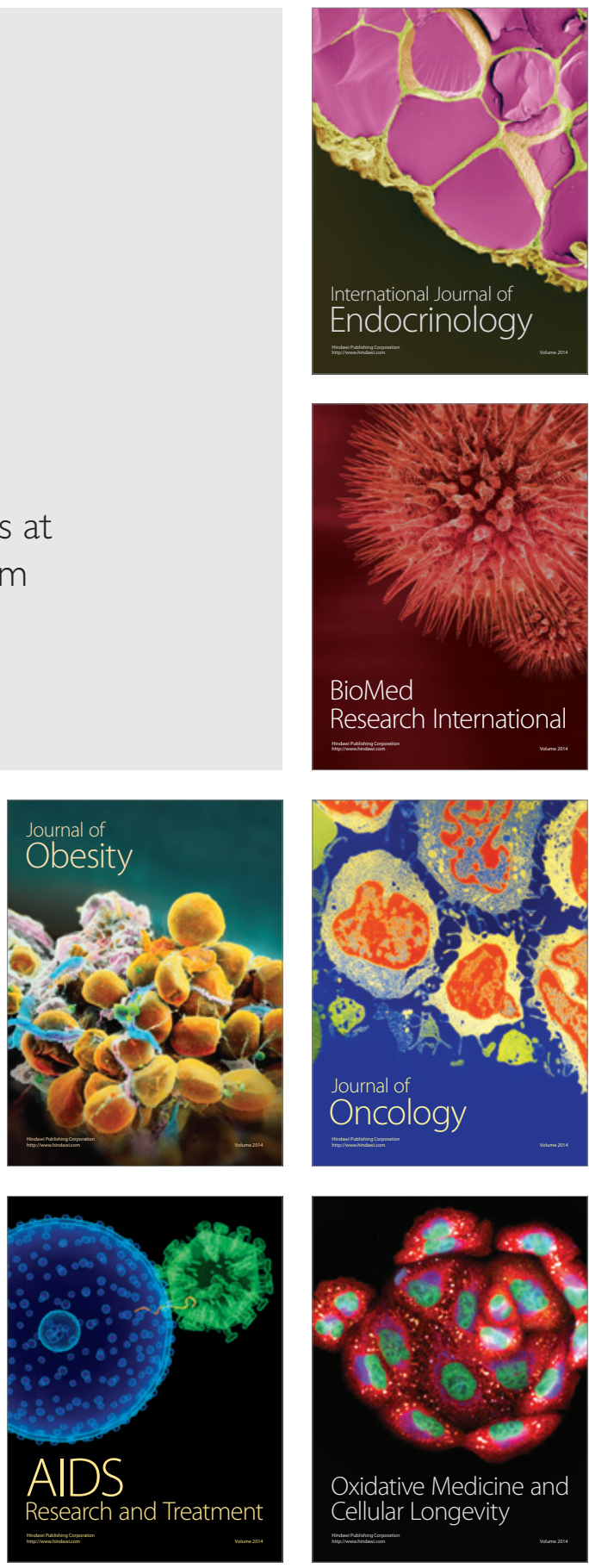